\title{
Curvas de dosagem para concreto convencional produzido com materiais da região de Porto Nacional (TO)
}

No Brasil, o concreto convencional é produzido, basicamente, pela mistura de água cimento, areia e brita ou seixo como agregado graúdo. Por muito tempo, a qualidade do concreto era definida apenas pela capacidade de resistência, assim a brita leva vantagem na escolha por apresentar maior valores de resistência. Mas atualmente, o seixo vem ganhando espaço no setor por apresentar um baixo custo em relação à brita. Assim, este trabalho tem por objetivo utilizar o método IPT/EPUSP para determinação das curvas de dosagem de concreto convencional utilizando a brita e o seixo rolado disponível na cidade de Porto Nacional (TO). A pesquisa utilizou como agregados para produção do concreto os materiais disponíveis nas jazidas que atendem a cidade de Porto Nacional (TO) e Cimento Portland CPII E32. A primeira etapa foi destinada à caracterização do material utilizado como agregado para produção do concreto. Para dosagem do concreto, foi adotado o método IPT/EPUSP. Este método foi desenvolvido pelo Instituto Tecnológico do Estado de São Paulo e a Escola Politécnica da USP. Os resultados mostraram que, mesmo a brita apresentando valores de resistência superiores, o seixo pode ser aplicado na produção de concretos convencionais até um determinado valor, atendendo às resistências exigidas de normas e à viabilidade econômica.

Palavras-chave: Dosagem; Concreto; Curvas; Ábaco.

\section{Dosage curves for conventional concrete produced with materials from Porto Nacional (TO)}

In Brazil, conventional concrete is produced basically by mixing water, cement, sand and gravel or pebble as coarse aggregate. For a long time, the quality of the concrete was defined only by the resistance capacity, so the crushed stone has the advantage in choosing to present higher strength values. But nowadays, the pebble has been gaining space in the sector by presenting a low cost in relation to gravel. Thus, this work aims to use the IPT / EPUSP method to determine the conventional concrete dosing curves using gravel and pebble available in the city of Porto Nacional (TO). The research used as aggregates for concrete production the materials available in the deposits that serve the city of Porto Nacional (TO) and Portland Cement CPII E32. The first stage was designed to characterize the material used as aggregate for concrete production. For concrete dosing, the IPT / EPUSP method was adopted. This method was developed by the São Paulo State Technological Institute and the USP Polytechnic School. The results showed that even gravel with higher strength values, pebble can be applied in the production of conventional concrete up to a certain value, meeting the required strength of standards and economic viability.

Keywords: Dosage; Concrete; Curves; Abacus.

Topic: Engenharia de Construção Civil

Reviewed anonymously in the process of blind peer.
Received: 11/04/2019

Approved: $15 / 07 / 2019$
Fábio Barreira Guimarães

Instituto Tocantinense Presidente Antônio Carlos, Brasil http://lattes.cnpq.br/3166684345437637

fabiobarreira.eng@gmail.com

José Silvério de Oliveira Júnior

Instituto Tocantinense Presidente Antônio Carlos, Brasil

http://lattes.cnpq.br/1869184317527602

silverio1professor@gmail.com
Referencing this:

GUIMARÃES, F. B.; OLIVEIRA JÚNOR, J. S.. Curvas de dosagem para concreto convencional produzido com materiais da região de Porto Nacional (TO). Engineering Sciences, v.7, n.2, p.40-52, 2019. DOI: http://doi.org/10.6008/CBPC2318-3055.2019.002.0005 


\section{INTRODUÇÃO}

A utilização de estruturas construídas da combinação de cal ou cimento natural com areia é datada de 3000 a.C em pirâmides egípcias. Mas foi no império romano, há cerca de 2000 anos, que teve início a aplicação do concreto na construção, como é conhecido hoje. A mistura era composta de cascalho, areia grossa e cal. Os romanos também utilizavam sangue de animais ou leite como aditivos e empregavam fios de cabelo de cavalos para reduzir a retração do concreto.

O concreto pode ter múltiplas aplicações dentro da construção civil, além de funções estruturais, pode ser utilizado nos mais diversos tipos de edificações como, por exemplo em casas de alvenaria, em rodovias, em usinas hidrelétricas, nas obras de saneamento, em pontes e até mesmo em plataformas de extração de petróleo. Estima-se que sejam consumidos 11 bilhões de toneladas de concreto ao ano sendo a segunda substancia mais utilizada no mundo, perdendo apenas pra água (PEDROSO, 2009).

O concreto é um composto formado pela mistura de cimento Portland, agregado graúdo (pedregulhos), agregado miúdo(areia) e água. Em casos especiais também é comum a utilização de aditivos que tem por objetivo alterar alguma propriedade da mistura para atender exigências construtivas. Quando o cimento entra em contato com a água, inicia-se a hidratação do mesmo formando uma pasta esta pasta preenche os vazios e faz a ponte de aderência entre os agregados.

A mistura resultante adquire consistência moldável e começa a ganhar resistência mecânica pela hidratação dos grãos de cimento (reação hidráulica), formando os cristais de etringita, produzindo, assim, um material com propriedades alcalinas importantes na proteção das armaduras e também apresenta alta resistência a compressão.

Com o crescimento da construção civil e ampla difusão dos sistemas estruturais em concreto armado $^{1}$, surgiram novas pesquisas, com o intuito de determinar com maior precisão os critérios de produção do concreto. Foram propostos diversos procedimentos de dosagem de concreto que visavam o desenvolvimento de métodos que permitem a determinação da proporção ideal dos componentes do concreto (água, cimento, areia e brita). Dentre eles, o método IPT/EPUSP demonstra versatilidade pelo fato de usar os materiais existentes na região, sem prévia classificação, demostrando grande potencialidade de aplicação na dosagem de concreto.

O concreto convencional é produzido, basicamente, pela mistura de água, cimento, areia e brita ou seixo como agregado graúdo². Por muito tempo, a qualidade do concreto era definida apenas pela capacidade de resistência, assim a brita leva vantagem na escolha por apresentar maior valores de resistência. Mas atualmente, o seixo vem ganhando espaço no setor por apresentar um baixo custo em relação à brita. Assim, surge uma grande problemática: qual material apresenta melhor custo-benefício para ser empregado como agregado graúdo na produção de concreto?.

\footnotetext{
${ }^{1}$ Concreto armado é um tipo de estrutura que utiliza armações feitas com barras de aço. Essas ferragens são utilizadas devido à baixa resistência aos esforços de tração do concreto, que tem alta resistência à compressão.

${ }^{2}$ Agregado, cujos grãos passam pela peneira com abertura de malha de $75 \mathrm{~mm}$ e ficam retidos na peneira com abertura de malha de $4,75 \mathrm{~mm}$. 
Assim, este trabalho tem por objetivo utilizar o método IPT/EPUSP para determinação das curvas de dosagem de concreto convencional, utilizando a brita e o seixo rolado disponível na cidade de Porto Nacional (TO). A ideia principal é realizar a análise comparativa entre os dois materiais e determinar até qual resistência a utilização do seixo é viável e econômica em relação à brita I, considerando o material e o preço de mercado praticado nesta região.

Este trabalho se justifica devido à escassez de informações a respeito da dosagem de concreto para a região de Porto nacional (TO). Os resultados destas pesquisas irão subsidiar toda cadeia envolvida no setor de construção civil na escolha do material a se utilizar como agregado graúdo em concreto convencionais, tornando o processo de escolha seguro e econômico. Além de ajudar no processo de escolha, as curvas podem ser utilizadas para determinação de novos traços a partir apenas da resistência requerida em projeto, ganhando tempo com isto, pois um novo estudo de dosagem requer no mínimo 28 dias para ficar concluído. As curvas podem ser utilizadas em obras que utilizem concreto convencional produzidos com seixo ou brita, cimento Portland CPII e abatimento de $100 \mathrm{~mm} \pm 20 \mathrm{~mm}$.

\section{REVISÃO TEÓRICA}

O concreto é definido como um material homogêneo formado pela mistura de cimento, agregado miúdo (areia), agregado graúdo (pedra ou brita) e água que tem suas propriedades desenvolvidas a partir do endurecimento da pasta de cimento. Quando o cimento é hidratado pela água, forma-se essa pasta de cimento que se adere aos agregados, formando uma mistura de fácil modelagem que quando endurecida adquire alta resistência a compressão (LIMA, 2014).

O concreto pode ser classificado como convencional ou de alta resistência. Tradicionalmente, é considerado como convencional o concreto com resistência a compressão inferior a 50mPa. Mas hoje, esta classificação é pouco efetiva pois a qualidade do cimento Portland é variável por região, resultando em valores diferentes de resistência em função da qualidade do cimento disponível. Então, a melhor definição para o concreto convencional seria o concreto que pode ter sua resistência alterada apenas pela relação entre água e cimento (a/c) sem a necessidade de utilização de aditivos (RECENA, 2002).

Sobre os agregados utilizado na produção de concreto convencionais a NBR 12655 define os mesmos como: "Material sem forma ou volume definido, geralmente inerte, de dimensões e propriedades adequadas para o preparo de argamassa e concreto" (ABNT, 2002). Os agregados são classificados como agregados graúdos, as matérias que apresentam grãos inferiores a 4,75mm e agregados graúdos que possuem granulometria variando de $4,75 \mathrm{~mm}$ a $75 \mathrm{~mm}$.

Para que o concreto convencional apresente bom desempenho, é necessário que os agregados atendam a alguns requisitos de utilização como: serem resistentes, duros, apresentar boa durabilidade, estarem limpos e livres de argila ou qualquer outro material fino que, em grande quantidade, possam interferir na ligação da pasta de cimento, ou na hidratação do concreto. As propriedades finais do concreto variam de acordo com essas características do agregado, principalmente quando o tamanho desses agregados for superior a 5mm, ou seja, os agregados graúdos (POMPEU NETO et al., 2011). 
Atualmente, o concreto convencional é produzido basicamente utilizando como agregado graúdo a brita granítica ou o seixo rolado. A brita granítica é produzida de forma artificial através do processo de britagem de rochas graníticas. Este agregado possui grande porcentagem de grãos irregulares, arestas vivas e superfície altamente rugosa. Já o seixo rolado é um material de origem natural que apresenta formas cuboides, arredondadas e superfície lisa. No ponto de vista de resistência, a brita tem mostrado melhores resultados; já o seixo vem ganhando espaço na construção civil devido aos eu baixo custo.

Para a correta produção do concreto, é necessário realizar o procedimento de dosagem que consiste na determinação das proporções ideais de cimento, agregado miúdo, agregado graúdo e da relação de água/cimento $(\mathrm{a} / \mathrm{c})$. O objetivo da dosagem é produzir um concreto que atenda as resistências de serviço, seja durável, tenha uma aparência adequada quando exposto, apresente condições adequadas de mistura e adensamento, tudo isso da forma mais econômica possível (ASSUNÇÃO, 2002).

Atualmente, existem vários métodos de dosagem de concreto disponíveis na literatura. Dentre esses, o método IPT/EPUSP é considerado o mais versátil e simples. O método tem por objetivo obter o comportamento mecânico e de trabalhabilidade do concreto, possibilitando um resultado preciso e único da proporção dos materiais do concreto. Este método é classificado como teórico-experimental, pois a primeira etapa dele ocorre em laboratório e a segunda etapa é analítica baseada nas leis de comportamento do concreto (TUNIKIAN et al., 2011).

O principal parâmetro para o método é a relação a/c, pois após se definir os materiais, a resistência torna-se única variando exclusivamente em função deste fator, desde que se considere sempre a mesma trabalhabilidade (slump test ${ }^{3}$ ) do concreto. Uma grande vantagem desse método é que não é necessário conhecer previamente as características do cimento e dos agregados, ainda assim, é sempre interessante, do ponto de vista da durabilidade, ter alguns dados laboratoriais sobre os materiais (TUNIKIAN et al., 2011).

\section{METODOLOGIA}

A pesquisa utilizou, como agregados para produção do concreto, os materiais disponíveis nas jazidas que atendem a cidade de Porto Nacional (TO) e Cimento Portland CPII E32. O município é rico em rochas máficas e ultramáficas associadas ao embasamento e rochas supracrustais, que são interpretadas como remanescentes ofiolíticos. Sendo encontrado no município grande abundancia de areias e seixos. Assim, o município é caracterizador por possuir um grande potencial de produção e extração de materiais por se tratar de uma região rica em minerais.

\section{Caracterização dos Agregados}

A primeira etapa foi destinada à caracterização do material utilizado como agregado para produção do concreto. Inicialmente todos os materiais (areia, seixo e brita) foram lavados para retirada de impurezas

${ }^{3}$ Slump test é um ensaio realizado para verificar a trabalhabilidade do concreto em seu estado plástico. 
e matéria orgânica como e em seguida colocados em estufa a $(105 \pm 5){ }^{\circ} \mathrm{C}$ durante $24 \mathrm{~h}$, como demostrado na figura 1.

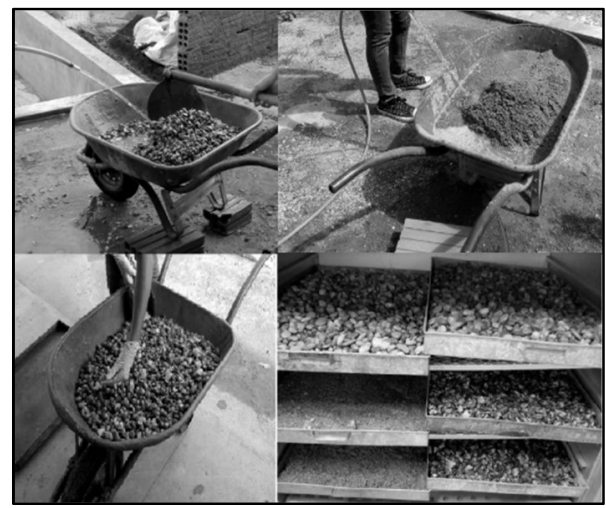

Figura 1: Lavagem e secagem em estufa de agregados.

Após a secagem dos matérias, foram realizados os ensaios de caracterização dos agregados, sendo realizados os ensaios de composição granulométrica, massa unitária e massa específica dos agregados miúdos (areia) e dos agregados graúdos (brita e seixo), como descrito na tabela 1. Na figura 2, são registrados os procedimentos executados.

Tabela 1: Caracterização das amostras para agregados.

\begin{tabular}{|c|c|c|}
\hline Ensaio & Norma Aplicada & Parâmetro de Avaliação \\
\hline Caracterização Granulométrica & NBR NM 248 & Distribuição Granulométrica \\
\hline Massa Específica dos Grãos & NBR 9776 & Massa Especifica dos Grãos \\
& NBR 9937 & Massa Unitária \\
\hline Massa Unitária & NBR 7251 & . \\
\hline
\end{tabular}

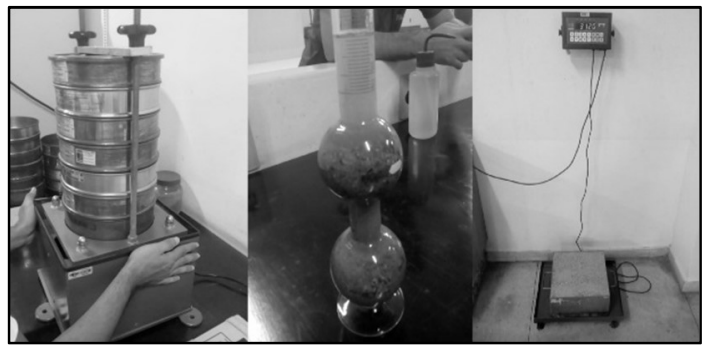

Figura 2: Ensaio de granulometria, massa específica e massa unitária, respectivamente.

\section{Dosagem do Concreto}

O método adotado para dosagem do concreto foi o IPT/EPUSP. Este método foi desenvolvido pelo Instituto Tecnológico do Estado de São Paulo e a Escola Politécnica da USP. O método prevê a dosagem do concreto com base em um teor ideal de argamassa $(\alpha)$, como previsto na equação $\alpha=1+a / 1+m$ em um traçobase $1: m$, onde ' $m$ ' representa a proporção de agregado em relação a quantidade de cimento e 'a' representa a proporção de agregado miúdo em relação ao cimento.

Nesta pesquisa foi adotado para ambos os agregados graúdo (seixo e brita) o traço base de 1:5,em massa utilizando a 1 o equação e a equação $p=m-a$, onde ' $p$ ' representa a proporção de agregado graúdo em relação a $1 \mathrm{~kg}$ de cimento, determinou-se o traço dos teores de argamassa começando com um $\alpha$ de 0,56 e aumentando em intervalos de 0,02, como descrito na tabela 2 . 
Tabela 2: Traços em função do teor de argamassa.

\begin{tabular}{|r|r|r|r|r|}
\hline \multicolumn{7}{|c|}{ TRAÇOS DE DOSAGEM EM FUNÇÃO DO TEOR DE ARGAMASSA } \\
\hline ALFA & A & A & P \\
\hline 0,56 & 5 & 2,36 & 2,64 \\
\hline 0,58 & 5 & 2,48 & 2,52 \\
\hline 0,6 & 5 & 2,6 & 2,4 \\
\hline 0,62 & 5 & 2,72 & 2,28 \\
\hline 0,64 & 5 & 2,84 & 2,16 \\
\hline 0,66 & 5 & 2,96 & 2,04 \\
\hline 0,68 & 5 & 3,08 & 1,92 \\
\hline 0,7 & 5 & 3,2 & 1,8 \\
\hline
\end{tabular}

Utilizando esses traços tabelados foi produzido o concreto inicial com $\alpha=0,56$ e corrigido os valores através de acréscimos até se atingir o teor de argamassa ideal, ou seja, até o concreto atingir o slump adotado de $100 \mathrm{~mm} \pm 20 \mathrm{~mm}$ (figura 3 ) e apresentar boa consistência verificada através de deslizamento da colher de pedreiro sobre a mistura e golpes para verificar como estava ocorrendo o desmoronamento. Depois de definido o teor de argamassa ideal no traço 1:5, utilizou se o mesmo teor para o traço rico em cimento 1:3,5 e para o traço pobre em cimento 1:6,5, no método IPT a quantidade de água é variável sendo adicionado pequenas quantidades até que os traços apresentem o slump pré-estabelecido.

Esse procedimento foi realizado de forma independente para a brita e para o seixo. Depois de determinadas as proporções ideais e os traços básico, rico e pobre foi realizada a moldagem dos copos de prova de $15 \mathrm{~cm} \times 30 \mathrm{~cm}$, pesagem dos corpos de provas para cálculo da massa unitária do concreto, e após 24h, foram armazenados em câmara saturada para cura no laboratório de construção civil do Instituto Tocantinense Presidente Antônio Carlos campus de Porto Nacional (TO), como ilustrado na figura 4.

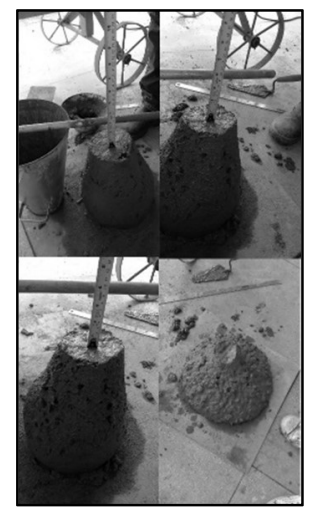

Figura 3: Sequência de Slump test até atingir o teor de argamassa ideal.

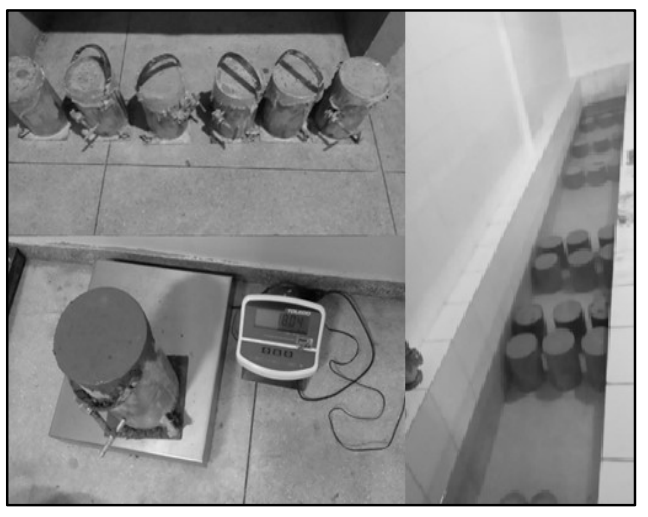

Figura 4: Modelagem dos corpos de prova 15x30 e acondicionamento em câmara saturada.

\section{Rompimento dos Corpos de Prova por Compressão}

Foram confeccionados um total de 36 corpos de provas de $15 \mathrm{~cm} \times 30 \mathrm{~cm}$, sendo 18 corpos de provas utilizando o seixo como agregado graúdo e os outros 18 utilizando brita granítica. Para cada tipo de agregado, foram utilizados três traços: o rico $(1: 3,5)$; o básico (1:5); e o pobre $(1: 6,5)$, que foram submetidos ao ensaio de compressão uniaxial nas idades de 7 dias e 28 dias.

O ensaio seguiu os procedimentos descritos na NBR 5738 - Procedimento para moldagem e cura de corpos de prova e na NBR 5739 - Ensaio de Compressão de Corpos de provas Cilíndricos. Os corpos de provas 
foram mantidos em meio saturado até a idade de rompimento pré-estabelecida. Para realização do ensaio de compressão axial, foi utilizado uma prensa hidráulica automática Control (figura 5). Os resultados foram registrados e os corpos de provas rompidos (figura 6) fotografados e descartados em containers de descarte da construção civil.

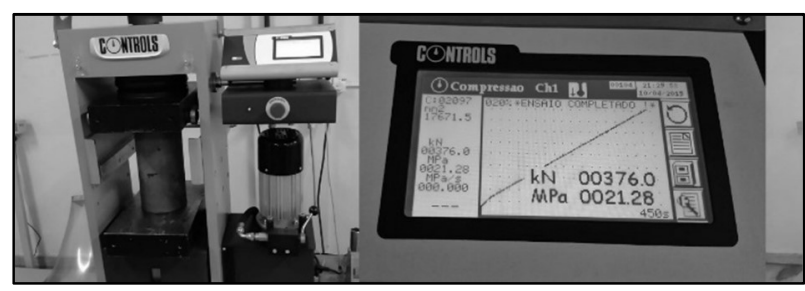

Figura 5: Prensa hidráulica automática Control.

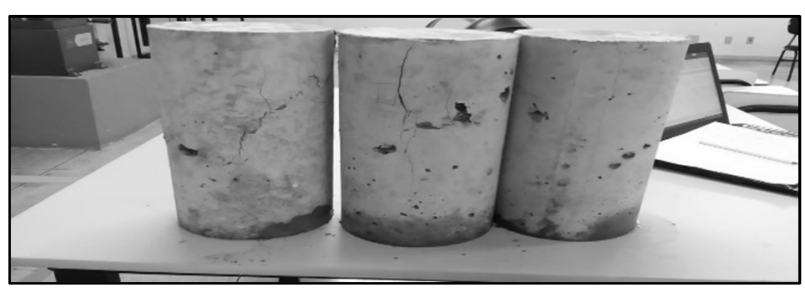

Figura 6: Corpos de provas rompidos.

\section{RESULTADOS}

\section{Caracterização dos Agregado}

Foi utilizado na confecção do concreto, como agregado miúdo, a areia, e como agregado graúdo, o seixo e a brita, disponíveis na jazida que atende a cidade de Porto Nacional. Mesmo o método utilizado sendo o IPT/EPUSP, que não necessita de conhecimento prévio das características do agregado, foram realizados tais ensaios visto que é importante conhecer esses dados para correto controle da produção de concreto ou para subsidiar trabalhos futuros que necessitem destes dados. Nas tabelas a seguir, são apresentados os resultados de massa específica e massa unitária da areia utilizada, que seguiu os procedimentos descritos na metodologia. No gráfico 1 é apresentada a curva granulométrica do agregado miúdo.

Tabela 3: Massa específica do agregado miúdo.

\begin{tabular}{|c|c|c|c|c|c|}
\hline \multicolumn{7}{|c|}{ Determinação da massa específica (Método da proveta) } \\
\hline \multicolumn{7}{|c|}{$1^{\circ}$ Determinação } & & 2 Determinação & $\mathrm{g}$ \\
\hline Mi agre & 500,1 & $\mathrm{G}$ & Mi agre & 500,06 & $\mathrm{~g}$ \\
\hline $\mathrm{Ml}$ água & 200 & $\mathrm{G}$ & $\mathrm{Ml}$ água & 200 & $\left(\mathrm{~cm}^{3}\right)$ \\
\hline $\mathrm{Lf}$ & 391 & $\left(\mathrm{~cm}^{3}\right)$ & $\mathrm{Lf}$ & 391 & $\left(\mathrm{~g} / \mathrm{cm}^{3}\right)$ \\
\hline $\mathrm{V}$ & 2,62 & $\left(\mathrm{~g} / \mathrm{cm}^{3}\right)$ & $\Gamma$ & 2,62 & 2,62 \\
\hline
\end{tabular}

Tabela 4: Massa Unitária do agregado miúdo.

\begin{tabular}{|l|c|c|c|}
\hline \multicolumn{3}{|c|}{ Agregado no estado solto Determinação da massa unitária } \\
\hline \multicolumn{1}{|c|}{ Determinação } & 1 a & $2 \underline{a}$ & 3 a \\
\hline Massa do recipiente $(\mathrm{kg})$ & 7,25 & 7,25 & 7,25 \\
\hline Massa do rec+amostra $(\mathrm{kg})$ & 31,2 & 31,1 & 31,1 \\
\hline Volume do recipiente $\left(\mathrm{dm}^{3}\right)$ & 15,121 & 15,121 & 15,121 \\
\hline Massa unitária $\left(\mathrm{kg} / \mathrm{dm}^{3}\right.$ & 1,584 & 1,577 & 1,577 \\
\hline \multicolumn{1}{|c|}{ Valor média $\left(\mathrm{kg} / \mathrm{dm}^{3}\right)$} & 1,579 \\
\hline
\end{tabular}

Os resultados mostram que a massa específica obtida para o agregado miúdo foi de $2,62 \mathrm{~g} / \mathrm{cm}^{3}$, e a sua massa unitária no estado solto foi de $1,579 \mathrm{~kg} / \mathrm{dm}^{3}$. Sobre o ensaio de granulométrica, ilustrado na figura 7 , permite classificar a areia como pertencente as areias grossas, mesmo observando que em determinadas peneiras a amostra apresentou características de areia média como observado no gráfico, em que certos pontos a curva granulométrica ultrapassa o limite mínimo das areias grossas. Nos dados a seguir, serão apresentados os resultados dos agregados graúdos, onde foram utilizados o seixo rolado e a brita para 
execução dos ensaios. Na tabela 5, são expressos os resultados para a massa específica do seixo, e na tabela 6 são dados os resultados do ensaio de massa unitária. No gráfico 2, é apresentada a distribuição granulométrica deste agregado.

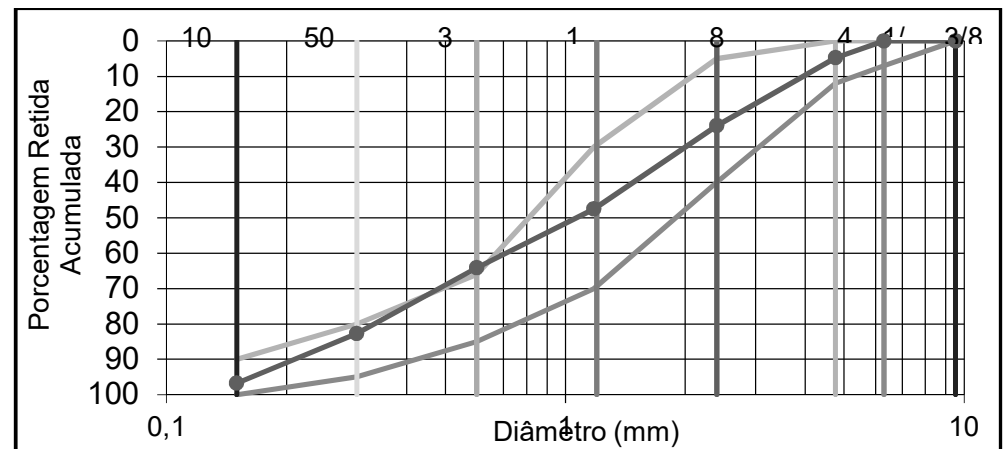

Gráfico 1: Curva granulométrica do agregado miúdo.

Tabela 5: Massa específica do agregado graúdo (seixo).

\begin{tabular}{|c|c|c|c|c|c|}
\hline \multicolumn{7}{|c|}{ Determinação da massa específica (Método da proveta) } \\
\hline Mi agre & 1000,38 & $\mathrm{~g}$ & Mi agre & 1000,38 & $\mathrm{~g}$ \\
\hline $\mathrm{Ml}$ água & 500 & $\mathrm{~g}$ & Ml água & 500 & $\mathrm{~g}$ \\
\hline $\mathrm{Lf}$ & 880 & $\left(\mathrm{~cm}^{3}\right)$ & $\mathrm{Lf}$ & 880 & $\left(\mathrm{~cm}^{3}\right)$ \\
\hline$\Gamma$ & 2,63 & $\left(\mathrm{~g} / \mathrm{cm}^{3}\right)$ & $\gamma$ & 2,63 & $\left(\mathrm{~g} / \mathrm{cm}^{3}\right)$ \\
\hline
\end{tabular}

Tabela 6: Massa unitária do agregado graúdo (seixo).

\begin{tabular}{|l|c|c|c|}
\hline \multicolumn{1}{|c|}{ Agregado no estado solto } & \multicolumn{3}{c|}{ Determinação da massa unitária } \\
\hline \multicolumn{1}{|c|}{ Determinação } & 1 a & 2a & 3 a \\
\hline Massa do recipiente $(\mathrm{kg})$ & 7,25 & 7,25 & 7,25 \\
\hline Massa do rec+amostra $(\mathrm{kg})$ & 33,9 & 33,9 & 33,9 \\
\hline Volume do recipiente $\left(\mathrm{dm}^{3}\right)$ & 15,121 & 15,121 & 15,121 \\
\hline Massa unitária $\left(\mathrm{kg} / \mathrm{dm}^{3}\right.$ & 1,762 & 1,762 & 1,762 \\
\hline \multicolumn{2}{|c|}{ Valor média $\left(\mathrm{kg} / \mathrm{dm}^{3}\right)$} & \multicolumn{2}{c|}{1,762} \\
\hline
\end{tabular}

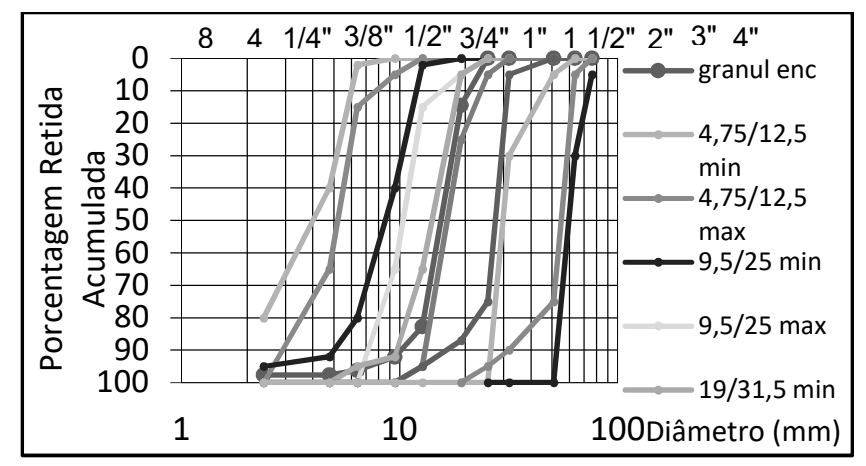

Gráfico 2: Curva granulométrica do agregado graúdo (seixo).

Os resultados da massa específica obtida para o seixo rolado foram de $2,6 \mathrm{~g} / \mathrm{cm}^{3}$ e a sua massa unitária no estado solto foi de $1,762 \mathrm{~kg} / \mathrm{dm}^{3}$. A partir do ensaio de granulométrica ilustrado no gráfico 2 permite classificar o seixo como pertencente as britas $\mathrm{n}-2$, que possuem dimensões variando de $19 \mathrm{~mm}$ a 31,5 .

Por fim, são apresentados os resultados dos ensaios laboratoriais sobre a caracterização da brita. Na tabela 7, é expresso o valor obtido no ensaio de massa específica e na tabela 8 é apresentados os valores da massa unitária da brita. No gráfico 3, foi ilustrado a distribuição granulométrica do agregado. Os resultados 
mostram uma massa específica de $2,7 \mathrm{~g} / \mathrm{cm}^{3}$ e uma massa unitária de $1,607 \mathrm{~kg} / \mathrm{dm}^{3}$. A brita é classificada também como brita 2, como descrito no gráfico 3.

Tabela 7: Massa específica do agregado graúdo (brita).

\begin{tabular}{|c|c|c|c|c|c|}
\hline \multicolumn{7}{|c|}{ Determinação da massa específica (Método da proveta) } \\
\hline \multicolumn{7}{|c|}{$1^{\circ}$ Determinação } & Mi agre & 1000,2 & $\mathrm{~g}$ \\
\hline Mi agre & 1000,4 & $\mathrm{~g}$ & $\mathrm{Ml}$ água & 500 & $\mathrm{~g}$ \\
\hline $\mathrm{Ml}$ água & 500 & $\mathrm{~g}$ & $\mathrm{Lf}$ & 870 & $\left(\mathrm{~cm}^{3}\right)$ \\
\hline $\mathrm{Lf}$ & 870 & $\left(\mathrm{~cm}^{3}\right)$ & $\gamma$ & 2,70 & $\left(\mathrm{~g} / \mathrm{cm}^{3}\right)$ \\
\hline$\Gamma$ & 2,70 & $\left(\mathrm{~g} / \mathrm{cm}^{3}\right)$ & & 2,70 \\
\hline
\end{tabular}

Tabela 8: Massa unitária do agregado graúdo (brita).

\begin{tabular}{|l|c|c|c|}
\hline \multicolumn{1}{|c|}{ Agregado no estado solto } & \multicolumn{3}{c|}{ Determinação da massa unitária } \\
\hline \multicolumn{1}{|c|}{ Determinação } & 1 a & 2 a & 3a \\
\hline Massa do recipiente $(\mathrm{kg})$ & 7,25 & 7,25 & 7,25 \\
\hline Massa do rec+amostra $(\mathrm{kg})$ & 31,65 & 31,7 & 31,3 \\
\hline Volume do recipiente $\left(\mathrm{dm}^{3}\right)$ & 15,121 & 15,121 & 15,121 \\
\hline Massa unitária $\left(\mathrm{kg} / \mathrm{dm}^{3}\right.$ & 1,614 & 1,617 & 1,591 \\
\hline \multicolumn{2}{|c|}{ Valor média $\left(\mathrm{kg} / \mathrm{dm}^{3}\right)$} & \multicolumn{3}{|c|}{1,607} \\
\hline
\end{tabular}

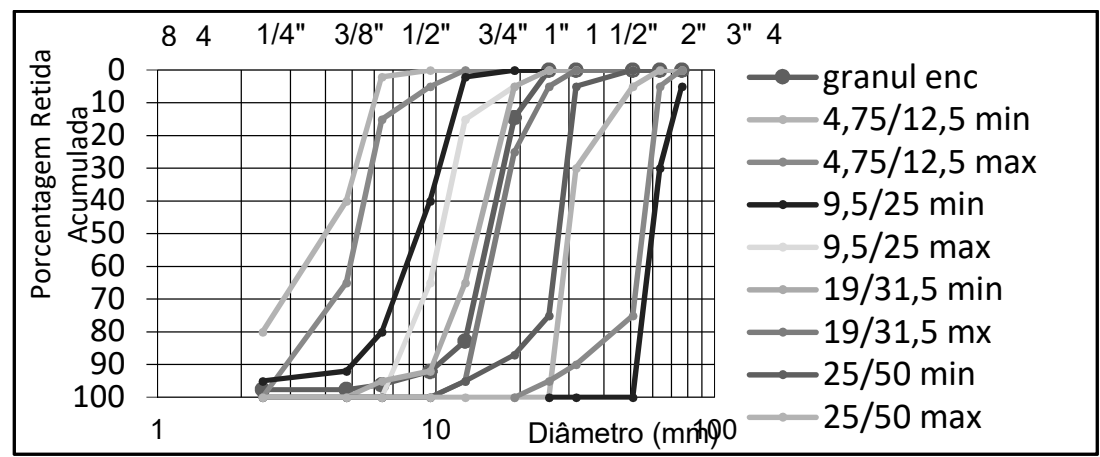

Gráfico 3: Curva granulométrica do agregado graúdo (brita).

\section{Curvas de Dosagem do Concreto Método IPT/EPUSP}

Serão apresentadas as curvas de dosagem obtidas utilizando o método IPT/EPUSP. A partir destas curvas, é possível determinar o traço de concreto ideal para atender as condições de resistência e de economicidade para qualquer concreto produzido, desde que utilizando os materiais disponíveis nas jazidas que abastecem a cidade Porto Nacional (TO) com característica granulométrica especificadas na seção caracterização do agregado e cimento Portland CPII-E32. Os resultados mostram as curvas de dosagem para seixo e brita como agregado graúdo nas idades de 7 e 28 dias. 0 teor de argamassa \% ( $\alpha$ ) adotado ideal neste estudo para o seixo foi de 0,6 e para a brita foi de 0,68 .

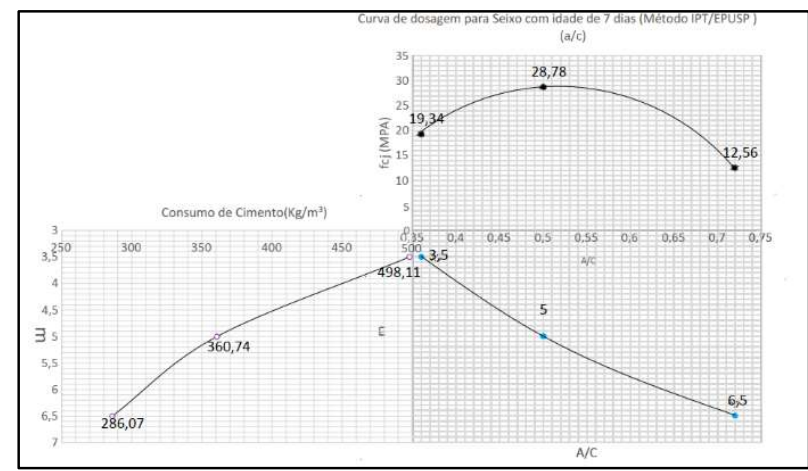

Gráfico 4: Curva de Dosagem (Seixo, 7 dias).

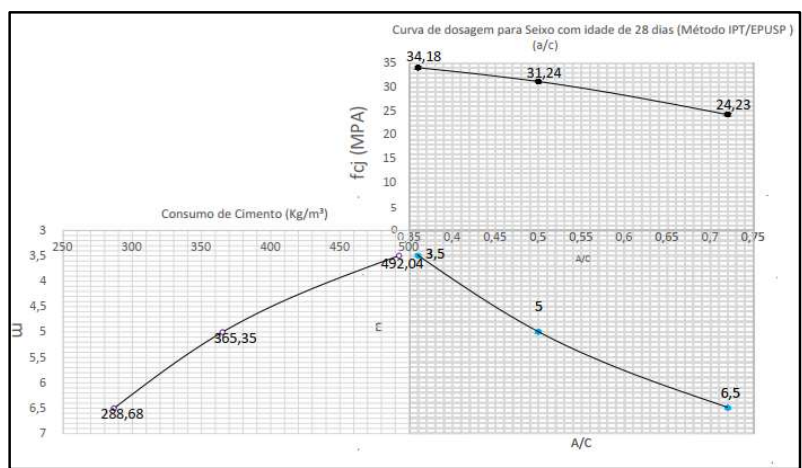

Gráfico 5: Curva de Dosagem (Seixo, 28 dias). 


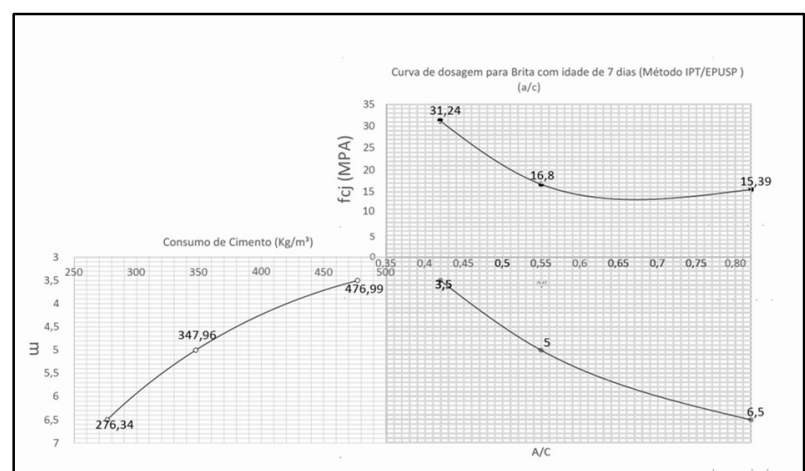

Gráfico 6: Curva de Dosagem (Brita, 7 dias).

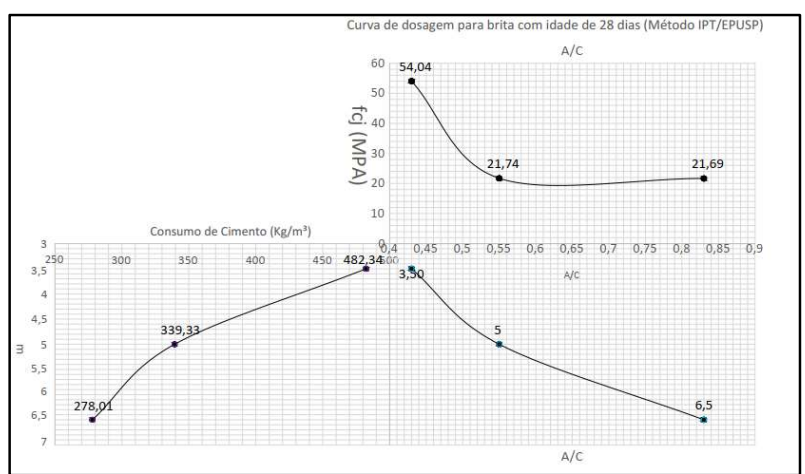

Gráfico 7: Curva de Dosagem (Brita, 28 dias).

\section{Comparação Econômica entre os Agregados Graúdos: Brita X Seixo}

Inicialmente, foi realizado um levantamento de preço na cidade Porto Nacional (TO), foram coletados os preços praticados em 3 fornecedoras diferentes. Os resultados individuais e o valor médio dos materiais estão expressos na tabela 9. Para o cimento foi adotado o valor médio de $\mathrm{R} \$ 27,00$ o saco de $50 \mathrm{~kg}$ e para a areia grossa adotou-se o valor médio de $\mathrm{R} \$ 70,000 \mathrm{~m}^{3}$.

Tabela 9: Levantamento do valor da Brita e Seixo.

\begin{tabular}{|c|c|c|}
\hline Fornecedora & Seixo $(R \$)^{3} \mathbf{m}^{3}$ & Brita $\left(\mathbf{R} \$ / \mathrm{m}^{\mathbf{3}}\right)$ \\
\hline Fornecedora 1 & 110 & 130 \\
\hline Fornecedora 2 & 110 & 128 \\
\hline Fornecedora 3 & 110 & 130 \\
\hline Média & 110,00 & 129,33 \\
\hline
\end{tabular}

Em seguida, foi realizada a determinação dos traços e do consumo de cimento, agregado miúdo e agregado graúdo em função dos fck de 30, 25 e $20 \mathrm{mpa}$, sendo utilizado as curvas de dosagens de 28 dias do seixo e da brita apresentados nos gráficos 5 e 7, respectivamente. Optou-se por desconsiderar as curvas de dosagens com idades de 7 dias por apresentarem dados duvidosos e resistência baixa, o que acarretaria em um consumo de concreto elevado e incondizente. Na tabela 8, são apresentados os dados de consumo e a tabela 10 demostra os preços dos materiais para produção de $1 \mathrm{~m}^{3}$ de concreto utilizando a brita. Na tabela 10, são apresentados os dados de consumo e a tabela 11 demostra os preços dos materiais para produção de $1 \mathrm{~m}^{3}$ de concreto utilizando a brita. Para o fck de 30mpa o seixo não apresenta resistência suficiente para atender seu fcj de 37,425mpa como observado no gráfico 5 .

Tabela 10: Dosagem do concreto utilizando a brita.

\begin{tabular}{|c|c|c|c|c|c|c|c|c|c|c|}
\hline Fck & $\mathrm{fcj}$ & $\mathrm{m}$ & $\mathrm{a} / \mathrm{c}$ & Cimento & A & P & A. Miúdo $(\mathrm{kg})$ & A. Graúdo $(\mathrm{kg})$ & A. Miúdo $\left(\mathrm{m}^{3}\right)$ & Brita $\left(\mathrm{m}^{3}\right)$ \\
\hline 30 & 37,425 & 4,2 & 0,476 & 411 & 2,536 & 1,664 & 1042,29 & 683,90 & 0,6600987 & 0,4255780 \\
\hline 25 & 32,425 & 4,4 & 0,49 & 391 & 2,672 & 1,728 & 1044,75 & 675,64 & 0,6616542 & 0,4204405 \\
\hline 20 & 27,425 & 4,66 & 0,511 & 368 & 2,848 & 1,811 & 1048,35 & 666,52 & 0,6639381 & 0,4147614 \\
\hline
\end{tabular}

Tabela 11: Custo unitário do concreto utilizando a brita.

\begin{tabular}{|c|c|c|c|c|}
\hline fck & Cimento (R\$/kg de concreto) & Areia (R\$/kg de concreto) & Brita (R\$/kg de concreto) & Preço para $1 \mathrm{~m}^{3}$ de concreto \\
\hline 30 & $\mathrm{R} \$ 221,94$ & $\mathrm{R} \$ 46,21$ & $\mathrm{R} \$ 55,04$ & $\mathrm{R} \$ 323,19$ \\
\hline 25 & $\mathrm{R} \$ 211,14$ & $\mathrm{R} \$ 46,32$ & $\mathrm{R} \$ 54,38$ & $\mathrm{R} \$ 311,83$ \\
\hline 20 & $\mathrm{R} \$ 198,72$ & $\mathrm{R} \$ 46,48$ & $\mathrm{R} \$ 53,64$ & $\mathrm{R} \$ 298,84$ \\
\hline
\end{tabular}

Tabela 12: Dosagem do concreto utilizando o seixo.

\begin{tabular}{|c|c|c|c|c|c|c|c|c|c|c|}
\hline fck & $\mathrm{fcj}$ & $\mathrm{m}$ & $\mathrm{a} / \mathrm{c}$ & Cimento & $\mathrm{A}$ & $\mathrm{P}$ & A. Miúdo $(\mathrm{kg})$ & A. Graúdo $(\mathrm{kg})$ & A. Miúdo $\left(\mathrm{m}^{3}\right)$ & Seixo $\left(\mathrm{m}^{3}\right)$ \\
\hline 30 & 37,425 & Nulo & Nulo & Nulo & Nulo & Nulo & Nulo & Nulo & Nulo & Nulo \\
\hline
\end{tabular}




\begin{tabular}{|c|c|c|c|c|c|c|c|c|c|c|}
\hline 25 & 32,425 & 4,42 & 0,442 & 406 & 2,25 & 2,16 & 914,312 & 880,208 & 0,57904496 & 0,4995505 \\
\hline 20 & 27,425 & 5,95 & 0,629 & 312 & 3,17 & 2,78 & 989,04 & 867,36 & 0,62637112 & 0,4922587 \\
\hline
\end{tabular}

Tabela 13: Custo unitário do concreto utilizando o seixo.

\begin{tabular}{|c|c|c|c|c|}
\hline Fck & Cimento (R\$/kg de concreto) & Areia (R\$/kg de concreto) & Seixo (R\$/kg de concreto) & Preço para $1 \mathrm{~m}^{3}$ de concreto \\
\hline 30 & nulo & Nulo & nulo & nulo \\
\hline 25 & $\mathrm{R} \$ 219,24$ & $\mathrm{R} \$ 40,53$ & $\mathrm{R} \$ 54,95$ & $\mathrm{R} 314,72$ \\
\hline 20 & $\mathrm{R} \$ 168,48$ & $\mathrm{R} \$ 43,85$ & $\mathrm{R} \$ 54,15$ & $\mathrm{R} \$ 266,47$ \\
\hline
\end{tabular}

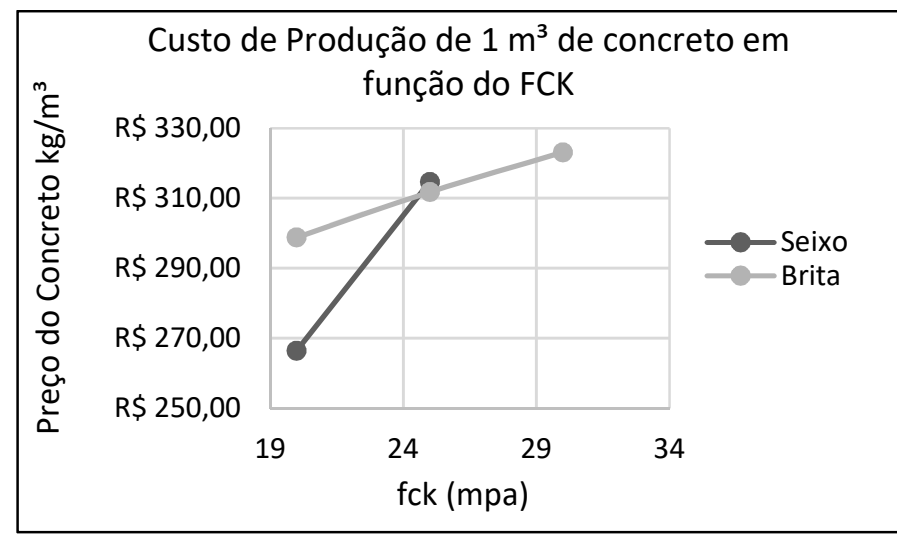

Gráfico 8: Custo do Concreto: Seixo vs Brita.

Os dados referentes ao comparativo entre os custos unitários de produção do concreto convencional utilizando o seixo e a brita como agregados graúdos estão sintetizados no gráfico 8. É possível notar que o seixo é economicamente viável para produção de concreto convencional até aproximadamente o fck de $24 \mathrm{mpa}$. Sendo aconselhável do ponto de vista econômico a utilização de brita para os concretos de fck superior a $25 \mathrm{mpa}$. Para concretos com fck de $30 \mathrm{mpa}$ ou mais o seixo não apresentou resistência aceitável mesmo utilizando um traço rico de 1:3.5, sendo necessário realizar novos ensaios para obtenção de dados para um concreto com traço mais rico em cimento ou utilizar um cimento de uma classe de resistência maior que o CPII - E32 utilizado neste trabalho.

\section{DISCUSSÃO}

Sobre os resultados obtidos quantos as curvas de dosagem a maioria dos padrões ocorreram como esperado. A resistência do concreto é inversamente proporcional ao fator água/cimento (a/c), ou seja, quanto maior a quantidade de cimento em relação a de água, mais resistente será o concreto, sendo esta uma das principais características dos concretos convencionais. Entretanto, para o concreto com traço rico do seixo rompido aos 7 dias (gráfico 4), sua resistência foi inferior ao traço padrão e ao traço pobre que possuíam um maior fator água/cimento, sendo esperado que o traço rico apresentasse maior desempenho. Já na amostra rompida aos 28 dias os valores de resistência se comportaram da forma esperada.

Segundo Alves (2000), concretos com um fator a/c alto possuem um ganho de resistência lento nas primeiras idades, enquanto concretos com a/c baixos tem ganho de desempenho rápidos nas primeiras idades, o que explicaria tal situação observada nos concretos ricos em cimento em que se utilizou o seixo como agregado graúdo. Quanto à comparação entre as resistências a compressão simples entre o seixo rolado e a brita granítica, a brita apresenta maiores valores de resistência em relação ao seixo. Observando 
o gráfico 5 e 7 também nota se que a faixa de resistência da brita que varia de 54,04 a 21, 69mpa é superior a faixa de resistência do seixo que é de 34,18 a 24,23mpa.

Corroborando assim, com Petrucci (2005), Alves (2000) afirma que o seixo rolado devido a sua forma arredondada e superfície lisa, apresenta uma baixa aderência a argamassa do concreto, tornando as suas propriedades mecânicas inferiores a brita, embora no ramo da construção civil seja necessário que, tanto a segurança e a economia sejam levadas em conta durante a definição dos materiais, não sendo suficiente afirmar que o brita é a melhor opção para produção do concreto apenas por apresentar maior valores de resistência.

Nesse sentido, o método IPT/EPUSP se mostra eficiente por proporcionar a dosagem de um concreto com teores de argamassa e trabalhabilidade adequadas a obras. Outro ponto positivo deste método é a possibilidade de determinação de um traço econômico adaptável ao tipo de concreto que se pretende obter (BOGGIO, 2000).

Ao analisar o gráfico 8, nota-se que, mesmo o seixo apresentando uma resistência inferior em relação à brita, o mesmo tem um grande potencial na utilização em concretos convencionais abaixo de $24 \mathrm{mpa}$. Acima deste valor, a brita torna-se economicamente viável pois mesmo com o valor do material sendo mais elevado, a partir dessa resistência o consumo de cimento e areia no concreto em que se utiliza o seixo é bem maior ultrapassando o valor unitário do $\mathrm{m}^{3}$ do concreto produzido com brita.

Segundo Brito (2015), é necessária uma maior quantidade de argamassa para aderir o seixo rolado, formando assim um concreto com boa trabalhabilidade, melhorando a coesão e a consistência do concreto. Embora, por consequência, ocorrerá o aumento gradativo do custo unitário do preço do concreto, até que não seja mais viável do ponto de vista econômico.

\section{CONCLUSÕES}

Conclui-se, com este trabalho, que o método IPT/EPUSP apesenta resultados confiáveis e eficientes na dosagem de concretos convencionais. As principais vantagens é a possibilidade de realizar a determinação do traço sem conhecer boa parte dos dados dos materiais utilizados como os agregados e os cimentos, o que proporciona rapidez de execução, podendo ser realizada a caracterização posteriormente. Os resultados são fiéis, pois se trata de um método experimental em que é observado o comportamento real do concreto em que será trabalhado.

A principal desvantagem do método é que as curvas têm um intervalo de resistência, e o mesmo limita a dosagem a estes intervalos, não sendo admitido valores superiores ou inferiores de resistência. Sobre a comparação entre o seixo rolado e a brita granítica, é possível concluir que, mesmo a brita apresentando valores de resistência superiores, o seixo pode ser aplicado na produção de concretos convencionais até um determinado valor, atendendo as resistências exigidas de normas e a viabilidade econômica.

Para os materiais disponíveis na cidade de Porto Nacional (TO) utilizando cimento Portland CPII-E32 o fck limite para o atendimento normativo pelo concreto, em que se utilizou o seixo foi de $26 \mathrm{mpa}$ e para os 
concretos acima de $24 \mathrm{mpa}$ a brita se tornou mais economicamente viável que o seixo. Fica como sugestão para trabalhos futuros a proposição de curvas de dosagens de concreto utilizando o método IPT/EPUSP e comparação do melhor agregado graúdo (Brita vs Seixo) para concretos especiais ou de alta resistência.

\section{REFERÊNCIAS}

ABNT. Associação Brasileira de Normas Técnicas. NBR 10520: informação e documentação: citações em documentos. Rio de Janeiro: ABNT, 2002.

ALVES, M. F.. Estudo comparativo de métodos de dosagem para concreto de alta resistência. Dissertação (Mestrado em Engenharia Civil) - Universidade Federal do Rio Grande do Sul, Porto Alegre, 2000.

ASSUNÇÃO, J. W.. Curvas de dosagem para concretos convencionais e aditivados confeccionados com materiais da região nordeste do Paraná. Tese (Doutorado) -

Universidade Federal de Santa Catarina, Florianópolis, 2002.

BOGGIO, A. J.. Estudo comparativo de métodos de dosagem de concretos de cimento Portland. Porto Alegre: UFRGS, 2000.

BRITTO, D. C.. Estudo comparativo do comportamento mecânico dos concretos produzidos com seixos rolados e britas graníticas como agregado graúdo da região de Teresina-PI. Dissertação (Mestrado em Engenharia Civil e Ambiental) - Universidade Federal de Campina Grande, Campina Grande, 2015.
LIMA, S. F.. Concreto e suas inovações. Ciências Exatas e Tecnológicas, v.1, n.1, p.31-40, 2014.

PEDROSO, F. L.. Concreto: as origens e a evolução do material construtivo mais usado pelo homem. Concreto e construções, v.53, p.14-19, 2009.

PETRUCI, E.. Concreto de cimento Portland. São Paulo: Globo, 2005.

POMPEU NETO, B. B.; OLIVEIRA, D. R. C.; RAMOS, D.. Efeitos do tipo, tamanho e teor de agregado graúdo no módulo de deformação do concreto de alta resistência. Matéria, v.16, n.2, 2011.

RECENA, F. A. P.. Dosagem e controle da qualidade de concretos convencionais de cimento Portland. Porto Alegre: EDPUCRS, 2002.

TUTIKIAN, B. F.; HELENE, P.. Dosagem dos concretos de cimento Portland. Concreto: Ciência e Tecnologia, n.12, 2011.

A CBPC - Companhia Brasileira de Produção Científica (CNPJ: 11.221.422/0001-03) detém os direitos materiais desta publicação. Os direitos referem-se à publicação do trabalho em qualquer parte do mundo, incluindo os direitos às renovações, expansões e disseminações da contribuição, bem como outros direitos subsidiários. Todos os trabalhos publicados eletronicamente poderão posteriormente ser publicados em coletâneas impressas sob coordenação da Sustenere Publishing, da Companhia Brasileira de Produção Científica e seus parceiros autorizados. Os (as) autores (as) preservam os direitos autorais, mas não têm permissão para a publicação da contribuição em outro meio, impresso ou digital, em português ou em tradução. 